\title{
How, Rather Than What Type of, Music Increases Empathy
}

\author{
TAL-CHEN RABINOWITCH \\ Institute for Learning \& Brain Sciences, University of Washington
}

\begin{abstract}
In their article on music and empathy, Greenberg, Rentfrow and BaronCohen propose to employ the Emphasizing-Systemizing (E-S) theory as a framework for analyzing the intrapersonal and social psychological processes that underlie the capacity of music to promote empathy. In particular, the authors consider the implications of E-S theory for autism, and speculate about which types of music might be most effective for increasing empathy in individuals with autistic spectrum conditions (ASC). The main premise of the article is that different personality types, characterized as empathizers versus systemizers, prefer different types of music, and that the key for increasing empathy with music is to choose the type of music that is most associated with empathizers. This commentary attempts to shift the focus of analysis from the type of music, to the more fundamental mechanisms by which music in general may promote empathy. From this alternative perspective E-S theory leads to surprising theoretical predictions about music, empathy, and ASC.
\end{abstract}

Submitted 2014 November 24; accepted 2014 November 26.

KEYWORDS: empathy, autism, musical preference, perception, performance

\section{WHAT TYPES OF MUSIC INCREASE EMPATHY?}

"IF one listens to the wrong kind of music, one will become the wrong kind of person." This famous claim by Aristotle represents an age-old belief that music has the capacity to mold character, and that different types of music influence us in distinct ways. Following this tradition, Greenberg et al. set out to identify what types of music should be most effective for promoting empathy. Their strategy is based on the rationale that those types of music that are most preferred by particularly empathic individuals might, in reverse, increase empathy in those that have a weaker capacity for empathy. The Empathizing-Systemizing (E-S) theory (Baron-Cohen, 2003; 2009) is used as a framework for characterizing individuals' cognitive styles according to their tendencies to empathize versus systemize. Empathizing consists of sensitivity to the emotions and mental states of other agents, whereas systemizing comprises responsiveness to the underlying parts and organization of non-agentive systems. The authors hypothesize that empathizers will tend to prefer music that is emotional, deep, reflective, romantic, and gentle, whereas systemizers will prefer energetic, thrilling, and forceful music. Moreover, since according to E-S theory individuals with autistic spectrum conditions (ASC) are extreme systemizers and poor empathizers, the authors expect ASC individuals to be drawn to music containing multiple patterns of complex instrumentation and intricate harmonic and rhythmic systems. The ultimate theoretical prediction made is that emotional, deep, reflective, romantic, gentle music, assumed to be the most appealing to empathizers, will be the most effective in enhancing empathy.

\section{HOW DOES MUSIC INCREASE EMPATHY?}

Which types of music increase empathy is an interesting question. However, it rests on the assumption that the type of music at all matters. Instead, it might be beneficial to first consider the more fundamental question of how music, in general, may promote empathy. Elsewhere (Rabinowitch, Cross, \& Burnard, 2012a; 2012b; Cross, Laurence, \& Rabinowitch, 2012), I have described in detail a theoretical framework linking music to empathy. The theory dissects human interaction through music into a hierarchy of motor, cognitive, emotional, and social states and actions such as movement, imitation, synchronization, and various other prominent elements. All of these entail certain proficiencies, which are attained through 
repeated exposure, but more importantly, active participation in music, especially in an interactive setting. Interestingly, in addition to being important for music, these basic proficiencies all appear to have a potential positive role also for promoting empathy. Thus, through transfer of learning, what is learned through music participation may be translated into an increased capacity for empathy.

As an example, let us consider synchronization, the coordination of action in time. Music is a temporal medium whose flow is almost always organized as a train of pulses in the form of beats, and whose pattern is typically dynamic and irregular. In order to perceive music, but especially in order to play music with others, one must be able to synchronize with a changing beat. Synchronization is thus an essential component of music perception and production (Merker, 1999). However, at the same time synchronization acts also as a prominent aligning mechanism enhancing attentional and motoric coordination and cohesion between listeners, and especially among performers (Cross, 2005, 2007). An increasing number of studies demonstrate a central function for beat-based synchronization in refining certain elements of social interaction, including a role in enhancing person perception (Macrae et al., 2008), social perception (Miles et al., 2009), social cooperation (Wiltermuth \& Heath, 2009), and increased affiliation (Hove \& Risen, 2009). Moreover, the continuous and mutual adjustment to another person's pace may align not just rhythm and movement, but also interpersonal affective dynamics (Cross, 2005; Cross, Laurence, \& Rabinowitch, 2012) and intentionality (Cross, 2005; Kirschner \& Tomasello, 2009). Such an acquired readiness and ability to attend and adjust to others and to coordinate with them might potentially contribute to reinforcing a capacity for, and willingness to, adapt also to someone else's emotional situation, and to thus experience empathy towards that person. In this way, participation in music may refine and develop a proficiency that might also be important for empathy. Similar analysis has been done for the other components of music, demonstrating that music is endowed with a unique blend of features that, if properly practiced, are predicted to promote empathy. Indeed, this music-empathy theory was the basis for the design of a yearlong intervention study that resulted in an enhanced capacity for empathy in children who participated in weekly group musical sessions, compared to parallel story-telling and drama sessions or no sessions at all (Rabinowitch, Cross, \& Burnard, 2012a).

\section{FROM SYSTEMIZING TO EMPATHIZING VIA MUSIC}

According to the music-empathy theory, how music is used is probably much more important than what type of music is used. The theory postulates that the most effective way to implicitly train individuals to become better empathizers through music is to engage them in musical group interaction. Listening or even playing alone is insufficient for acquiring the full breadth and richness that interpersonal musical interaction can offer. Moreover, for the group interaction to be effective it must emphasize the empathypromoting components of music, such as synchronization. For this reason, in the intervention study mentioned above children were asked to perform together specific musical tasks and games, each tailored to reflect one of these components. As long as the participants experienced and acquired proficiency for synchronization with one another, for example, the particular type of music was of less importance.

That being said, it is not unreasonable to expect that certain types of music might be more effective for strengthening certain types of empathy-enhancing skills. Consider, for example, the type of music that Greenberg et al. propose as being most appealing to those with ASC: music containing multiple patterns of complex instrumentation and intricate harmonic and rhythmic systems. Such music might actually be very effective for refining and developing the ability to synchronize, since much more attention and skill are required in order to keep up with the complex rhythm. In turn, according to the musicempathy theory, greater and richer proficiency in synchronization is expected to have a larger positive impact on social interaction and particularly on empathy, since the individual is now better trained in sensing, following, and responding to what is transpiring in others. However, there is a very important step that should be noted. Since the aim is to become sensitive and responsive to other people, the effect relies on engaging with the complex musical rhythm, in an other-directed context, as opposed to a self-directed one. Thus, instead of exposing ASC individuals to "empathic" music, as prescribed by the authors, it might actually be more advisable to encourage them to engage in musical group interactions of whatever music they prefer. If they enjoy complex rhythms, then there is a good chance that repeatedly experiencing such rhythms during a joint musical activity will boost their ability to synchronize with others, equipping them with the kind of cognitive tools and attitude that are most beneficial for empathy. 


\section{NOTES}

Correspondence can be addressed to: Dr. Tal-Chen Rabinowitch, Institute for Learning \& Brain Sciences, Portage Bay Building, University of Washington, Seattle, 98195. E-mail: talchenr@uw.edu.

\section{REFERENCES}

Baron-Cohen, S. (2003). Essential difference: Men, women, and the extreme male brain. London: Penguin.

Baron-Cohen, S. (2009). Autism: The Empathizing-Systemizing (E-S) theory. Annals of the New York Academy of Sciences, 1156(1), 68-80.

Cross, I. (2005). Music and meaning, ambiguity and evolution. In D. Miell, R. MacDonald, \& D. Hargreaves (Eds.), Musical communication (pp. 27-43). Oxford: Oxford University Press.

Cross, I. (2007). Music and cognitive evolution. In L. Barrett \& R. Dunbar (Eds.), Oxford handbook of evolutionary psychology (pp. 649-667). Oxford: Oxford University Press.

Cross, I., Laurence, F., \& Rabinowitch, T. (2012). Empathic creativity in musical group practices. In G. McPherson \& G. Welch (Eds.), The Oxford handbook of music education (pp. 337-353). Oxford University Press.

Hove, M. J., \& Risen, J. L. (2009). It's all in the timing: Interpersonal synchrony increases affiliation. Social Cognition, 27(6), 949-960.

Kirschner, S., \& Tomasello, M. (2009). Joint drumming: Social context facilitates synchronization in preschool children. Journal of Experimental Child Psychology, 102(3), 299-314.

Macrae, C. N., Duffy, O. K., Miles, L. K., \& Lawrence, J. (2008). A case of hand waving: Action synchrony and person perception. Cognition, 109(1), 152-156.

Merker, B. E. (1999). Synchronous chorusing and the origins of music. Musicae Scientiae, special issue on rhythm, musical narrative, and origins of human communication, 59-73.

Miles, L. K., Nind, L. K., \& Macrae, C. N. (2009). The rhythm of rapport: Interpersonal synchrony and social perception. Journal of Experimental Social Psychology, 45(3), 585-589.

Rabinowitch, T., Cross, I., \& Burnard, P. (2012a), Long-term musical group interaction has a positive influence on empathy in children. Psychology of Music, 41(4), 484-498.

Rabinowitch, T., Cross, I., \& Burnard, P. (2012b), Musical group interaction, intersubjectivity and merged subjectivity. In D. Reynolds \& M. Reason (Eds.), Kinesthetic Empathy in Creative and Cultural Practices (pp. 109-120). Bristol, UK: Intellect Press.

Wiltermuth, S. S., \& Heath, C. (2009). Synchrony and cooperation. Psychological Science, 20(1), 1-5. 